OPEN ACCESS

Edited by:

Gabriela Topa,

National University of Distance

Education (UNED), Spain

Reviewed by:

Angelica Arace,

University of Turin, Italy

Elisabetta Sagone,

University of Catania, Italy

*Correspondence:

Simona De Stasio

s.destasio@/umsa.it

Specialty section

This article was submitted to

Organizational Psychology,

a section of the journal

Frontiers in Psychology

Received: 08 July 2019 Accepted: 23 September 2019

Published: 17 October 2019

Citation:

De Stasio S, Fiorilli C, Benevene P, Boldrini F, Ragni B, Pepe A and

Maldonado Briegas JJ (2019)

Subjective Happiness and

Compassion Are Enough to Increase

Teachers' Work Engagement?

Front. Psychol. 10:2268.

doi: 10.3389/fpsyg.2019.02268

\section{Subjective Happiness and Compassion Are Enough to Increase Teachers' Work Engagement?}

\author{
Simona De Stasio ${ }^{1 *}$, Caterina Fiorilli ${ }^{1}$, Paula Benevene ${ }^{1}$, Francesca Boldrini ${ }^{1}$, \\ Benedetta Ragni ${ }^{1}$, Alessandro Pepe ${ }^{2}$ and Juan José Maldonado Briegas ${ }^{3}$
}

${ }^{1}$ Department of Human Sciences, Libera Università Maria SS. Assunta, Rome, Italy, ${ }^{2}$ Department of Human Studies University of Milano-Bicocca, Milan, Italy, ${ }^{3}$ Department of Business Management and Sociology, University of Extremadura, Badajoz, Spain

The present quantitative multi-trait cross-sectional study aims to gain a better understanding of the network of relationship between subjective happiness, compassion, levels of work engagement, and proactive strategies (self- and coregulation) in a sample of teachers. Participants were 187 full-time in-service teachers (89\% female; age $M=48.5$; $S D=7.88$ ) from Rome, Italy. We hypothesized that subjective happiness and compassion of early childhood teachers would be related with work engagement in such a way that subjective happiness would promote the engagement of teachers. In a similar fashion, we theorized that subjective happiness would be positively related to self- and co-regulation strategies and that proactive strategies would be in turn associated to work engagement. As expected, the results revealed that subjective happiness and compassion showed effects on work engagement and that this association among constructs was mediated by the role of proactive strategies ( $\beta=0.22, p<0.001 ; \beta=0.37, p<0.001$, respectively). Proactive strategies also have a significant direct effect on work engagement $(\beta=0.56$, $p<0.001$ ). The study's findings suggest the importance of investing in the quality of the working environment.

Keywords: subjective happiness, compassion, work engagement, Italian early childhood teachers, proactive strategies

\section{INTRODUCTION}

Recent studies suggest that the relational nature of the early childhood education work environment bears key implications for teachers' well-being. Teaching is conducted in a social setting that involves not only direct interaction with children and their parents (Kremenitzer and Miller, 2008) but also cooperation with colleagues, head teachers, and other workgroup members (Leiter et al., 2012). According to Johnson et al. (2012), teachers see the school work environment as comprising three main components: working relationships with colleagues, the school principal's leadership, and school culture, all of which can contribute to teacher work satisfaction and retention rates. Teachers' everyday social interactions in the workplace are characterized by major emotional involvement, while positive relational bonds can represent a crucial protective factor for their job satisfaction and well-being (Saarni, 1999; Albanese et al., 2014; Fiorilli et al., 2015; Benevene et al., 2018a). The literature recognizes that individual dispositional variables, such as perceived subjective well-being and compassion toward others, influence the quality of teachers' working experience (Hargreaves, 2000; Morgeson and Humphrey, 2006; Warr, 2007; Boehm and Lyubomirsky, 2008; Lilius et al., 2008; Underwood, 2009; Benevene et al., 2018b). A positive atmosphere at school fosters 
job satisfaction and work engagement (Hoy and Spero, 2005), which, in turn, enhance job performance (Xanthopoulou et al., 2009). A number of studies found that teachers benefit from being compassionate, suggesting that affect plays a key role in work engagement (Brief and Weiss, 2002; Barsade et al., 2003; Hareli and Rafaeli, 2008; Robinson et al., 2013). Furthermore, Nislin et al. (2016) reported that good quality teamwork among teachers helps them to select effective strategies for coping with stressful work conditions. It is therefore of interest to investigate whether dispositional variables, such as subjective happiness and compassion, together with socio-contextual factors, such as self/co-regulated proactive strategies, predict the work engagement of early childhood (0-6 years) teachers.

Fredrickson's (2001) "Broaden-and-build theory of positive emotion" suggests that frequent positive affect triggered by subjective happiness and compassion at work will influence teachers' work outcomes. According to this theory, experiencing positive emotions at work contributes to broadening workers' individual mindsets, enabling them to build up their personal resources in terms of enhanced sensitivity and positive attitudes toward their workplace (Fredrickson, 2013). In educational settings, experiencing positive affect can lead early childhood teachers to form positive emotional associations with their workplace, progressively helping them to view it more positively, and fostering their emotional vigor and organizational commitment (Fredrickson, 2001; Fredrickson et al., 2003).

\section{DISPOSITIONAL VARIABLES AND WORK ENGAGEMENT}

Personal experience in the workplace can be influenced by multiple individual factors: among these, subjective happiness and dispositional positive affect toward others have recently been shown to wield a particularly strong influence (Burger and Caldwell, 2000; Morgeson and Humphrey, 2006; Warr, 2007; Boehm and Lyubomirsky, 2008; Lilius et al., 2008).

Happiness may be viewed as a dispositional measure of subjective well-being; it can help to explain why some individuals report greater self-perceived well-being as a function of life changes, while others report the same amount of well-being regardless of life events (Lyubomirsky and Lepper, 1999). Some authors use the term "subjective wellbeing" in preference to "happiness", on the grounds that the former has been more precisely defined in the scientific literature (Diener et al., 2017). In 1999, Lyubomirsky and Lepper introduced the concept of "subjective well-being" as a dispositional factor capable of explaining individual differences in coding, interpreting, and responding emotionally to life events (Lyubomirsky, 2001). A body of research suggests that perceived subjective well-being can influence the way people adapt to situations, events, and everyday life (Lucas, 2007; Luhmann et al., 2012).

As posited by the above-mentioned "Broaden-and-BuildTheory of positive emotions" (Fredrickson, 2001), subjective well-being contributes to predicting how people will manage and experience their work environment (Lyubomirsky et al., 2005).
According to Fredrickson (2001), frequent positive affect leads people to broaden their cognitive and behavioral repertoire and thereby to reinforce their store of personal resources such as self-efficacy, resilience, and optimism. Studies have shown that high dispositional subjective well-being is associated with positive work outcomes, superior performance, success, and higher levels of perceived social support from colleagues (Staw and Barsade, 1993; Staw et al., 1994; Burger and Caldwell, 2000; Boehm and Lyubomirsky, 2008). Happier workers are more likely to engage in altruistic and cooperative behaviors, thus enhancing both the general atmosphere and all-around productivity in the workplace (Borman et al., 2001; Lee and Allen, 2002; Miles et al., 2002; Ilies et al., 2006; Boehm and Lyubomirsky, 2008). They also learn to manage workload and stress more effectively, and make better work-related decisions (Staw and Barsade, 1993; Iverson et al., 1998; Morgeson and Humphrey, 2006; Warr, 2007).

Although several studies have identified a relationship between subjective happiness and work engagement, this association has yet to be investigated in-depth in relation to school and educational settings (Bakker and Oerlemans, 2016). In one of the few studies on the topic, Kim and Shin (2016) noted that early education teachers' happiness contributes to predicting their educational strategies, the quality of their interaction with the children, and their ability to foster positive social interaction in the classroom.

Among the dispositional variables that can affect workplace well-being, "compassion" is widely described in the literature as comprising three components: perceiving other people's suffering; reacting to it in terms of empathizing with the other person's discomfort; and offering a behavioral response with the aim of alleviating the other's suffering (Davis, 1983; Clark, 1997; Kanov et al., 2004; Dutton et al., 2006; Miller, 2007). Lilius et al. (2008) reported that compassionate behaviors in the workplace can have long-lasting effects on how individuals experience their work; compassion may be expressed by providing colleagues with emotional support, or by facilitating them in organizing their work, for example, by allowing them more flexible working hours (ibidem).

Although compassionate behaviors are a characteristic feature in many occupational contexts (Eldor and Shoshani, 2016), only a limited number of studies have examined the relationship between compassion and work-related experience (O'Brien, 2006; Tehan and Robinson, 2009).

Early education settings are particularly dependent on compassionate conduct, given that teachers provide crucial care to infants and children (Kremenitzer, 2005; Sutton and Wheatley, 2003; Kremenitzer and Miller, 2008). Compassion in the education sector has mainly been viewed as an expression of a teacher's attitude toward his/her pupils. However, this is an unduly restrictive definition: teachers also express compassion toward other adults such as their teaching colleagues, and thus can also be the recipients of affection and positive emotions. Compassion among teachers can enhance their feelings of emotional connection to their work and strengthen the association between organizational support and work commitment (Eldor and Shoshani, 2016). Some authors have investigated how compassion and proactive coping strategies 
are related to one another, as well as their effects on teacher adaptability and job satisfaction, and general classroom atmosphere (Mason et al., 2014; Mauno et al., 2016).

\section{THE ROLE OF PROACTIVE STRATEGIES IN EARLY CHILDHOOD TEACHERS' WORK ENVIRONMENT}

In the school setting, the term "coping strategies" refers to teachers' cognitive and behavioral efforts to reduce, tolerate, or manage work-related stress (Lazarus, 1993; Sharplin et al., 2011; Parker et al., 2012).

"Self-regulated" coping strategies are generated by individual teachers, with a view to managing stressful work situations (Zimmerman, 2002; Boekaerts and Corno, 2005). When teachers manage stressful scenarios by drawing on the social resources made available to them by their community of colleagues, these strategies may be defined as "co-regulated" (Järvelä et al., 2010).

Considering the highly social nature of educational and school settings, it is reasonable to assume that teachers typically coregulate their behavior in order to effectively cope with stressful conditions. Soini et al. (2010) found that, in schools, teachers who feel positively toward their work environment often use externally oriented problem-solving strategies and co-regulate their behavior with colleagues. Teachers who report high levels of support from colleagues are less likely to intend giving up teaching, as compared to those who report finding low levels of social support in the work setting (Pomaki et al., 2010). Proactive strategies help individuals to appropriately direct their behaviors, attain pre-set goals, and reduce their risk of burnout (Xanthopoulou et al., 2009; Devos et al., 2012).

When teachers experience job satisfaction and motivation, this generates a positive social atmosphere (Alhija and Fresko, 2010; Skaalvik and Skaalvik, 2011). According to Fredrickson (2001), positive affect fosters more creative and flexible use of available strategies. Teachers who are engaged with their work are significantly more inclined to deploy active and reflective approaches to problem-solving (Soini et al., 2010). The use of proactive strategies not only reduces the risk of burnout but also contributes to the development of a positive work environment and to increased job involvement. Their degree of efficacy appears to be closely related to the quality of teachers' social interactions, suggesting that co-regulation plays a key role in prompting and sustaining proactive intervention.

\section{WORK ENGAGEMENT}

Work engagement may be defined as "a state of fulfilment characterized by vigor, dedication, and absorption" (Schaufeli et al., 2002). The term "vigor" describes an energetic, effortful, and persistent approach to one's work; "dedication" denotes a high level of involvement, accompanied by a sense of meaningfulness, enthusiasm, and inspiration; the term "absorption" indicates concentration and feeling engrossed in one's work, such that the time spent working passes quickly (ibidem).

Work engagement is a predictor of work-related wellbeing, at both the individual and organizational levels (Bakker et al., 2008). In the school setting, work engagement strongly predicts job performance, reduced intention to quit teaching, positive teacher-student relationships, and student academic achievement (Bakker et al., 2006, 2008; Duckworth et al., 2009; Salanova et al., 2010).

Potential links between individual dispositional variables, such as subjective well-being and levels of work-engagement, have been explored in the literature (Field and Buitendach, 2011; Huynh et al., 2014; Rodríguez-Muñoz et al., 2014; Bakker and Oerlemans, 2016), but inadequately so in relation to educational and school settings (Pillay et al., 2005; Chan, 2009). Indeed, to date, subjective well-being in teachers has been viewed as an outcome of work engagement, rather than one of its potential antecedents (Tadić et al., 2013; Sirisunhirun and Dhirathiti, 2015).

Among individual dispositional resources, compassion at work has emerged as a strong predictor of work engagement (Mason et al., 2014; Mauno et al., 2016), being positively associated with teachers' levels of vigor, dedication, and satisfaction. It is also negatively associated with burnout, reflecting its status as a key resource for coping with stress-related burden (Eldor and Shoshani, 2016). Receiving constructive feedback and professional recognition from colleagues and superiors significantly affects job performance (Klusmann et al., 2008; Xanthopoulou et al., 2009), promoting job engagement and satisfaction (Peeters and Rutte, 2005; Kokkinos, 2007; Stoeber and Rennert, 2008).

\section{AIMS OF THE STUDY}

The present quantitative multi-trait cross-sectional study aims to gain a better understanding of the network of relationship between subjective happiness, compassion, levels of work engagement and proactive strategies (self- and co-regulation) in a sample of early childhood teachers. More specifically, we were first interested in evaluating the degree of fit of an integrated structural model with empirical data and then to assess the cumulative network by decomposing total effects in direct and indirect effects among considered variables.

Based on previous research, we expected that subjective happiness and compassion of early childhood teachers would be related with work engagement in such a way that subjective happiness would promote the engagement of teachers. In a similar fashion, we theorized that subjective happiness would be positively related to self- and co-regulation strategies and that proactive strategies would be in turn associated to work engagement. Finally, and most germane for the present paper, the representation of the network of association in an integrated structural model supported the theoretical viewpoints (Borrelli et al., 2014) considering subjective happiness, work engagement as dynamically shaping the social endeavor in which teachers are involved during their daily profession. 


\section{MATERIALS AND METHODS}

\section{Participants and Procedure}

Our sample was composed of 187 full-time in-service teachers ( $89 \%$ female) from Rome, Italy. Ages ranged from 27 to 63 $(M=48.5 ; S D=7.88)$ In terms of marital status, $56.5 \%$ were married, $21.6 \%$ were single, $18.4 \%$ were separated/divorced, and $1.6 \%$ were widowed; $65 \%$ of participants had children. Length of teaching experience ranged from 1 to 32 years $(M=17.23$ years, $S D=14.23)$. The study population was a convenience sample and may not be taken as representative of the entire population of Italian teachers given that all participants were based in Central Italy. The authors organized plenary assemblies in kindergarten schools to inform the teachers about the aims of the research and the procedures for completion of the questionnaires. All participants signed informed consent forms and were assured anonymity and confidentiality. The research protocol was approved by the Ethics Committee of LUMSA University, Rome. The original versions of questionnaires were initially translated from English into Italian and then back-translated into English to check the alignment with the original versions.

\section{Measures}

The Subjective Happiness Scale (Lyubomirsky and Lepper, 1999) is a four-item scale that assesses subjective happiness, using a seven-point Likert scale. The first two items ask people to rate how they are generally happy about their life ( $1=$ not a very happy person, 7 = a very happy person) and how happy they are in comparison with their peers ( $1=$ less happy, $7=$ more happy) (e.g., "Compared with most of my peers, I consider myself less happy ... more happy").

The last two items ask respondents to what extent the characterization of a happy and of an unhappy person describe themselves $(1=$ not at all, $7=$ a great deal $)$. Higher scores on this measure indicate greater subjective happiness. It is utilized in the Italian version adapted by De Stasio et al. (2017). Prior studies have reported Cronbach's alpha coefficients for the SHS from 0.79 to 0.94 (Lyubomirsky and Lepper, 1999).

The Santa Clara Brief Compassion Scale (Hwang et al., 2008) is a five-item scale; it assesses compassion and its link to prosocial behaviors. The scale includes items related to two facets of compassion: "emotionally connecting with other people's suffering" (e.g., "When I hear about someone going through a difficult time, I feel a great deal of compassion for him or her") and "acting to help them" (e.g., "I often have tender feelings toward people when they seem to be in need"). It is a shortened version of Sprecher and Fehr's (2005) Compassionate Love Scale (the correlation between the two scales is $r=0.95$ ) and it refers to non-intimate (i.e., strangers) rather than to close others. It is utilized in the original version translated in Italian through back-translation carried out by the authors. All items were rated on a seven-point Likert-type scale ranging from 1 (completely disagree) to 7 (completely agree), and higher scores are indicative of greater compassion. Cronbach's alpha was 0.87 .

The Utrecht Work Engagement Scale [UWES-17; Schaufeli et al., 2006, Italian version of UWES-17, validated by Balducci et al. (2014)] assesses work engagement. The scale is composed of 17 items, grouped into three subscales, namely, vigor (six items), dedication (five items), and absorption (six items) (e.g., "At my job, I feel strong and vigorous"). All items are scored on a sevenpoint frequency rating scale ranging from 0 (never) to 6 (always). Cronbach's alpha was 0.96 .

The Proactive Strategy scale (Salmela-Aro, 2009) consists of seven items, measuring two factors of proactive strategies: (a) self-regulation (4 items) and (b) co-regulation (3 items), meaning, respectively, the ability to identify and use resources for coping with stressors and the ability to seek and receive social support from colleagues (e.g., "I can set limits to my work assignments"; "I'm able to support the colleagues who feel strain in their work"). It is utilized in the original version translated in Italian through back-translation carried out by the authors. All items are rated on a seven-point Likert-type scale, ranging from 1 (completely disagree) to 7 (completely agree). Cronbach's alpha was 0.67 .

\section{Analytical Strategy Preliminary Analysis}

First, chi-square tests and correlational analysis were conducted to identify potentially confounding interrelationships among participants' demographic characteristics (age and gender) and the measures under study. Second, the statistical distribution of the data was explored for each of the measures. None of the kurtosis and skewness values were in excess of the recommended cutoffs $[-1,+1]$. Mahalanobis' distance $(p<0.001)$ was calculated for all scores in order to identify and skip any multivariate outliers. As a result, one extreme multivariate value was omitted from the analyses.

\section{Structural Equation Modeling}

The cumulative network of relationships among the variables of interest was analyzed via structural equation modeling (SEM), implemented using AMOS (Arbuckle and Wothke, 2006), version 21.0. This analytical strategy involves statistically testing a hypothesized set of direct and indirect paths among variables to evaluate the extent to which it fits the empirical data, yielding a measure known as goodness of fit. In the current study, we followed standard recommendations for the evaluation of a given SEM model (Bagozzi and Edwards, 1998; Hu and Bentler, 1999; Hair et al., 2010) by adopting two different types of fit index: absolute and relative. The absolute indexes selected were $\chi^{2}$ and normed- $\chi^{2}$ (NC) [a non-statistically significant $\chi^{2}$ value and NC values of under 2.0 indicate good fit (Hair et al., 2010)]. The relative indices adopted were the root mean square error of approximation (RMSEA), normed fit index (NFI), non-normed fit index (NNFI), comparative fit index (CFI), and standardized root mean square residual (SRMR). In this case, the thresholds set for good model fit were: RMSEA $<0.07$ (Schermelleh-Engel et al., 2003), NFI > 0.95, NNFI > 0.95 (Marsh, 2004), and CFI > 0.95 (Hu and Bentler, 1999). Finally, in keeping with current literature on the use of SEM (e.g., MacKinnon et al., 2004), we estimated confidence limits using both Monte Carlo simulation and bootstrapping methods with a set of random samples $(k=500)$. 


\section{RESULTS}

Table 1 reports correlations and descriptive statistics (means and standard deviations) for all the variables under study. Subjective happiness was statistically significant and slightly correlated with teachers' self-regulation strategies $(r=0.15, p<0.005)$, coregulation strategies $(r=0.19, p<0.001)$, and work engagement $(r=0.21, p<0.001)$. In a similar fashion, the correlations between compassion and work engagement $(r=0.42, p<0.001)$, teachers' self- regulation $(r=0.28, p<0.001)$, and co-regulation strategies $(r=0.31, p<0.001)$ were positive and statistically significant. Both teachers' self-regulation $(r=0.38, p<0.001)$ and co-regulation $(r=0.47, p<0.001)$ strategies were significantly correlated with work engagement.

The estimation of the conceptual model (see Figure 1) allowed us to test the hypothesis that the pattern of association between measures of subjective happiness, compassion, proactive strategies, and work engagement can be modeled within a single integrated model. SEM revealed that relative indexes of fit were generally robust $\left[\chi^{2}(33)=0.279, p=0.870 ; \mathrm{NC}=0.14\right]$, suggesting a good degree of fit between the conceptual model and the actual empirical data. Further information about the practical significance of the model was provided by analysis of absolute indexes (RMSEA $=0.003, p_{\text {close }}=0.913$, SRMR $=0.001$, NFI $=0.998$, CFI $=0.999)$, all of whose values fell within the recommended cutoff points. The analysis of total effects (standardized weights) and the subsequent decomposition in direct and indirect effects estimated by the structural equations model allowed us to explore more specific research hypotheses. The results suggested that subjective happiness wielded a positive total effect $[\beta=0.22, p=0.005$, 95th C.I. $(0.607-1.18)]$ on work engagement, composed of a non-statistically significant direct effect $[\beta=0.04, p=0.590$, 95th C.I. $(-0.209-0.448)]$ and of an indirect effect via proactive strategies $[\beta=0.18, p=0.006$, 95th C.I. (0.420-1.22)]. The latent endogenous variable compassion strategies reported a statistically significant total and positive standardized total effect on work engagement $[\beta=0.37, p=0.014$, 95th C.I. (0.701-1.28)], composed of both a significant direct effect on work engagement $[\beta=0.15, p=0.013$, 95th C.I. (2.26$4.47)]$ and a significant indirect effect via proactive strategies $[\beta=0.22, p=0.009$, 95th C.I. $(0.148-0.810)]$. Compassion strategies also reported a statistically significant direct effect on proactive strategies: $\beta=0.39, p=0.011$, 95th C.I. (0.047-0.192).

TABLE 1 | Bivariate correlations and descriptive statistics (means and standard deviations) for all the variables under study.

\begin{tabular}{lccccc}
\hline & $\mathbf{1}$ & $\mathbf{2}$ & $\mathbf{3}$ & $\mathbf{4}$ & $\mathbf{5}$ \\
\hline 1. Work engagement & 1 & & & & \\
2. Subjective happiness & $0.205^{* *}$ & 1 & & & \\
3. Compassion & $0.420^{* *}$ & 0.147 & 1 & & \\
4. Co-regulation strategies & $0.468^{* *}$ & $0.194^{* *}$ & $0.310^{* *}$ & 1 & \\
5. Self-regulation strategies & $0.385^{* *}$ & $0.151^{*}$ & $0.276^{* *}$ & $0.435^{* *}$ & 1 \\
M & 84.3 & 19.8 & 29.4 & 18.1 & 22.4 \\
S.D. & 13.1 & 3.8 & 4.1 & 2.2 & 3.8 \\
\hline
\end{tabular}

${ }^{* *} p<0.01 ; * p<0.05$.
With regard to the proactive strategies, the results evidenced their medium, positive, and statistically significant total effect on work engagement $[\beta=0.56, p=0.013$, 95th C.I. (2.26-4.47)], meaning that the greater teachers use self- and co-regulated strategies, the higher their levels of work engagement.

\section{DISCUSSION}

In the present study, we set out to investigate the network of relationships between subjective happiness, compassion, work engagement, and the use of proactive strategies (both self- and co-regulated) in a sample of early childhood teachers. We found that subjective happiness and compassion had direct positive effects on work engagement. Furthermore, the effect of subjective happiness and compassion on work engagement was mediated by the deployment of proactive strategies. Early childhood teachers' self- and co-regulation (i.e., their ability to identify and use resources for coping with stressors as well as to seek and receive social support from colleagues) also had a direct positive effect on work engagement, lending support to the idea that using such strategies enhances early childhood teachers' degree of involvement in their work. We now discuss the different roles played by the variables under study considering their direct and indirect effects on levels of work engagement.

\section{The Direct and Indirect Effects of Subjective Happiness and Compassion on Work Engagement}

Our data confirm previous findings reported in the literature about, on the one hand, the relationship between positive emotions (triggered by subjective happiness and compassion at work) and proactive strategies and, on the other, the link between the use of proactive strategies and personal involvement in one's work. For example, the present results are in line with studies reporting the beneficial effects of positive emotions on individuals' behavioral and cognitive repertoires (Fredrickson, 2001), as well as the effects of personal and relational proactive strategies on engagement (Salmela-Aro et al., 2011).

Considering that work engagement is the opposite of burnout, the present findings are also in line with previous research identifying subjective happiness and compassion as key personal resources for coping with work-related stress and burnout (Field and Buitendach, 2011; Huynh et al., 2014; Bakker and Oerlemans, 2016). Vice versa, past studies found that depressive symptoms are negatively related to work engagement (Upadyaya et al., 2016), again indirectly confirming the importance of subjective happiness as a contributor to work engagement. Indeed, subjective happiness has been shown to enhance both teaching and broader life experience, generating work engagement by fostering more effective deployment of job resources (Bakker et al., 2014). Nevertheless, to the best of our knowledge, subjective happiness has not previously been investigated as a potential antecedent of work engagement among kindergarten teachers.

A further key finding of this study was that compassion had a positive effect on work engagement. Again, this finding is in line with previous studies showing compassion to be a 


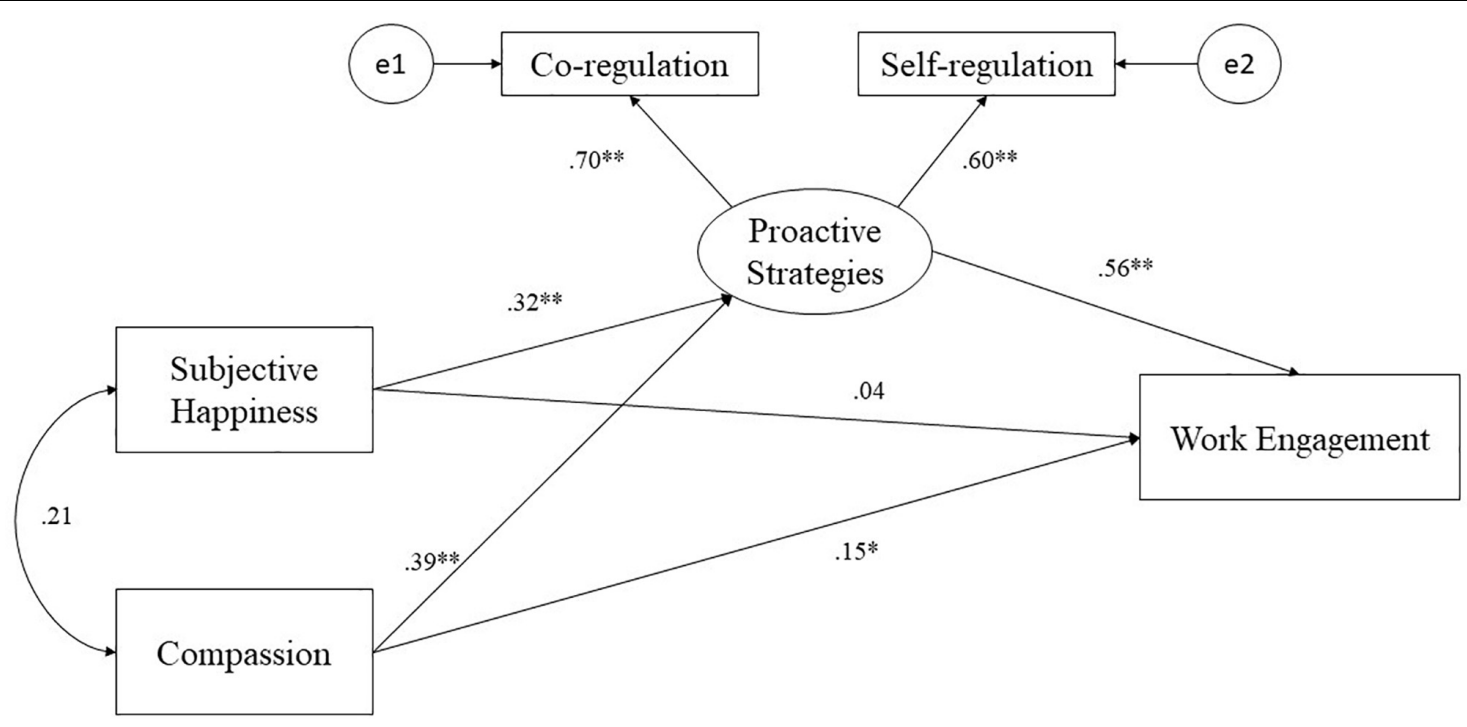

FIGURE 1 | Results of the structural equation model. Standardized direct effect were reported. ${ }^{*} p<0.05,{ }^{* *} p<0.01$.

correlate of work commitment (Mason et al., 2014; Eldor and Shoshani, 2016). In this respect, Tremblay and Messervey (2011) argued that compassion may generate work engagement by buffering the impact of job demands on work-related strain. More generally, personal resources such as subjective happiness and compassion may determine how job resources-the strongest predictors of work engagement-are perceived (Lorente et al., 2014; Diener et al., 2015).

The effect of compassion and subjective happiness on work engagement is greatly increased when mediated by coping strategies.

Overall, our findings suggest that the self-reported deployment of self- and co-regulated proactive strategies on the part of early childhood teachers is positively associated with their work-related well-being, in terms of self-perceived work engagement. Existing studies suggest that teachers who experience positive involvement in their work are more inclined to draw on active and reflective problemsolving strategies (Soini et al., 2010; Simbula et al., 2011). Furthermore, experiencing positive emotions prompts more creative and flexible use of available coping strategies (Fredrickson, 2001), enabling teachers to tackle challenges in innovative and original ways (Lyubomirsky et al., 2005; Linnenbrink-Garcia et al., 2011).

In keeping with the present findings, adopting proactive strategies has been associated with more effective regulation of behavior and greater adaptability to the work environment on the part of teachers. In fact, the deployment of proactive strategies is related to the ability to manage work-related burden and feel positively involved in it (Butler, 2007; Salmela-Aro et al., 2011; Devos et al., 2012), even when workload is perceived as particularly intense (Pomaki et al., 2010).

The literature suggests that the use of proactive strategies may also be associated with lower levels of perceived stress and more effective use of existing personal and relational resources on the part of teachers (De Caroli and Sagone, 2012; Pietarinen et al., 2013; Bermejo-Toro et al., 2016; Tikkanen et al., 2017). A proactive personal attitude is linked with work engagement and takes the form-for example-of actively seeking support from one's teaching colleagues and setting stimulating goals (Bakker et al., 2012). Pietarinen et al. (2013) examined the relationshipin a sample of teachers-between their deployment of proactive strategies, workplace difficulties, and perceived adaptability.

The present findings confirm the role of proactive strategies as protective factors. Again, this bears out previous research suggesting that when teachers are able to use multiple coping strategies, this protects the teacher community from emotional exhaustion (Kyriacou, 2001; Howard and Johnson, 2004; Austin et al., 2005; Carmona et al., 2006).

Thus, self-perceived work engagement may be seen as a social outcome that is dependent on teachers' subjective wellbeing at work and may be significantly enhanced by the deployment of self- and co-regulative strategies on the part of the community of education practitioners. Using proactive strategies allows teachers to simultaneously regulate their own behavior and their working environment, thus enhancing working environment fit.

Ad hoc interventions for fostering the use of proactive strategies should be designed, with a view to reducing teachers' risk of burnout and increasing their engagement and positive involvement in the educational setting (Pietarinen et al., 2013).

\section{CONCLUSION AND IMPLICATIONS}

The present study advances our understanding of early childhood teachers' work engagement, by evaluating the contributions of subjective happiness, compassion, and proactive strategies to work engagement within a single model. It shows that subjective happiness and compassion at work trigger positive feelings, 
which in turn contribute to enhancing pre-school teachers' attitudes and work outcomes. Another key outcome is that the dispositional variables happiness and compassion need to be mediated by proactive strategies, undertaken both individually and jointly with colleagues, for teachers to attain a fuller sense of work engagement. A novel aspect of the current research is that it specifically analyzed the work-related well-being of a group of early childhood teachers, a population whose work engagement has been little investigated in the literature to date (Hall-Kenyon et al., 2014; Cumming, 2017). Nonetheless, it is well known that children's well-being is closely related to teachers' wellbeing and work engagement: for example, when teachers perceive their work community in a positive light, this is associated with better classroom teaching quality (McGinty et al., 2008). Early education environments are characterized by multiple stressors including the children's needs, relationships with families and colleagues, and organizational issues (Kelly and Berthelsen, 1995; Rentzou, 2012; Jovanovic, 2013; Faulkner et al., 2014; Nislin et al., 2016), with potentially detrimental repercussions on teacher-child interaction and infant development (e.g., De Schipper et al., 2008).

In conclusion, the current findings suggest that early childhood teachers are more inclined to reinforce their work engagement by drawing on positive workplace relationships than by relying on their dispositional characteristics. Positive interpersonal relationships in the school setting promote work engagement and protect early childhood teachers from the risk

\section{REFERENCES}

Albanese, O., Pepe, A., Fiorilli, C., and Gabola, P. (2014). Emozioni, supporto sociale ed esaurimento emotivo negli insegnanti: una relazione complessa. Psicologia e Scuola 31, 15-21.

Alhija, F. N. A., and Fresko, B. (2010). Socialization of new teachers: does induction matter? Teach. Teach. Educ. 26, 1592-1597. doi: 10.1016/j.tate.2010. 06.010

Arbuckle, J. L., and Wothke, W. (2006). AMOS User's Guide 7.0. Spring House, PA: AMOS Development Corporation.

Austin, E. J., Saklofske, D. H., and Egan, V. (2005). Personality, well-being and health correlates of trait emotional intelligence. Pers. Individ. Differ. 38, 547558. doi: 10.1016/j.paid.2004.05.009

Bagozzi, R. P., and Edwards, J. R. (1998). A general approach for representing constructs in organizational research. Organ. Res. Methods 1, 45-87. doi: 10. $1177 / 109442819800100104$

Bakker, A. B., Demerouti, E., and Sanz-Vergel, A. I. (2014). Burnout and work engagement: the JD-R approach. Annu. Rev. Organ. Psychol. Organ. Behav. 1, 389-411. doi: 10.1146/annurev-orgpsych-031413-091235

Bakker, A. B., Emmerik, H. V., and Euwema, M. C. (2006). Crossover of burnout and engagement in work teams. Work Occup. 33, 464-489. doi: 10.1177/ 0018726705055967

Bakker, A. B., and Oerlemans, W. G. (2016). Momentary work happiness as a function of enduring burnout and work engagement. J. Psychol. 150, 755-778. doi: 10.1080/00223980.2016.1182888

Bakker, A. B., Schaufeli, W. B., Leiter, M. P., and Taris, T. W. (2008). Work engagement: an emerging concept in occupational health psychology. Work Stress 22, 187-200. doi: 10.1080/026783708023 93649

Bakker, A. B., Tims, M., and Derks, D. (2012). Proactive personality and job performance: the role of job crafting and work engagement. Hum. Relat. 65, 1359-1378. doi: 10.1177/0018726712453471 of burnout. Based on these findings, we strongly recommend intervention in the domains of personal resources and workrelated well-being in the interest of optimizing early childhood teachers' work engagement.

\section{DATA AVAILABILITY STATEMENT}

All datasets generated for this study are included in the manuscript/supplementary files.

\section{ETHICS STATEMENT}

The study involving human participants was reviewed and approved by the Scientific Board of LUMSA University, Rome. The participants provided their written informed consent to participate in this study.

\section{AUTHOR CONTRIBUTIONS}

$\mathrm{SD}, \mathrm{CF}$, and PB designed and carried out the study, contributed to the analysis of the results and to the writing of the manuscript. $\mathrm{BR}, \mathrm{FB}, \mathrm{AP}$, and JM collected the data, and contributed to the analysis of the results and to the writing of the manuscript. $\mathrm{PB}$, $\mathrm{SD}$, and JM supervised the study design and the manuscript draft.

Balducci, C., Fraccaroli, F., and Schaufeli, W. B. (2010). Psychometric properties of the italian version of the utrecht work engagement scale (UWES-9): a cross-cultural analysis. Eur. J. Psychol. Assess. 26, 143-149.

Barsade, S., Brief, A. P., Spataro, S. E., and Greenberg, J. (2003). "The affective revolution in organizational behavior: The emergence of a paradigm," in Organizational Behavior: A Management Challenge, ed. J. Greenberg, (Mahwah, NJ: Lawrence Erlbaum).

Benevene, P., Ittan, M. M., and Cortini, M. (2018a). Self-esteem and happiness as predictors of school teachers' health: the mediating role of job satisfaction. Front. Psychol. 9, 1-5. doi: 10.3389/fpsyg.2018.00933

Benevene, P., Wong, Y. H. P., Fiorilli, C., and De Stasio, S. (2018b). A cross-national comparison on subjective well-being of kindergarten teachers: Hong Kong and Italy. Front. Psychol. 9:1-11. doi: 10.3389/fpsyg.2018. 02626

Bermejo-Toro, L., Prieto-Ursúa, M., and Hernández, V. (2016). Towards a model of teacher well-being: personal and job resources involved in teacher burnout and engagement. Educ. Psychol. 36, 481-501. doi: 10.1080/01443410.2015. 1005006

Boehm, J. K., and Lyubomirsky, S. (2008). Does happiness promote career success? J. Career Assess. 16, 101-116. doi: 10.1177/1069072707308140

Boekaerts, M., and Corno, L. (2005). Self-regulation in the classroom: a perspective on assessment and intervention. Appl. Psychol. 54, 199-231. doi: 10.1111/j. 1464-0597.2005.00205.x

Borman, W. C., Penner, L. A., Allen, T. D., and Motowidlo, S. J. (2001). Personality predictors of citizenship performance. Int. J. Select. Assess. 9, 52-69. doi: 10. 1111/1468-2389.00163

Borrelli, I., Benevene, P., Fiorilli, C., D’amelio, F., and Pozzi, G. (2014). Working conditions and mental health in teachers: a preliminary study. Occup. Med. 64, 530-532. doi: 10.1093/occmed/kqu108

Brief, A. P., and Weiss, H. M. (2002). Organizational behavior: affect in the workplace. Annu. Rev. Psychol. 53, 279-307. doi: 10.1146/annurev.psych.53. 100901.135156 
Burger, J. M., and Caldwell, D. F. (2000). Personality, social activities, jobsearch behavior and interview success: distinguishing between PANAS trait positive affect and NEO extraversion. Moti. Emot. 24, 51-62. doi: 10.1023/A: 1005539609679

Butler, R. (2007). Teachers' achievement goal orientations and associations with teachers' help seeking: examination of a novel approach to teacher motivation. J. Educ. Psychol. 99, 241-252. doi: 10.1037/0022-0663.99. 2.241

Carmona, C., Buunk, A. P., Peiro, J. M., Rodríguez, I., and Bravo, M. J. (2006). Do social comparison and coping styles play a role in the development of burnout? Cross-sectional and longitudinal findings. J. Occup. Organ. Psychol. 79, 85-99. doi: 10.1348/096317905X40808

Chan, D. W. (2009). Orientations to happiness and subjective well-being among Chinese prospective and in-service teachers in Hong Kong. Educ. Psychol. 29, 139-151. doi: 10.1080/01443410802570907

Clark, C. (1997). Misery and company: Sympathy in everyday life. Chicago, IL: Chicago University Press, doi: 10.2307/2654341

Cumming, T. (2017). Early childhood educators' well-being: an updated review of the literature. Early Childhood Educ. 45, 583-593. doi: 10.1007/s10643-0160818-6

Davis, M. H. (1983). Empathic concern and the muscular dystrophy telethon: empathy as a multidimensional construct. Pers. Soc. Psychol. Bull. 9, 223-229. doi: $10.1177 / 0146167283092005$

De Caroli, M. E., and Sagone, E. (2012). Professional self representation and risk of burnout in school teachers. Proc. Soc. Behav. Sci. 46, 5509-5515. doi: 10.1016/j. sbspro.2012.06.466

De Schipper, E. J., Riksen-Walraven, J. M., Geurts, S. A. E., and Derksen, J. J. L. (2008). General mood of professional caregivers in child care centers and the quality of caregiver-child interactions. J. Res. Pers. 42, 515-526. doi: 10.1016/j. jrp.2007.07.009

De Stasio, S., Fiorilli, C., Benevene, P., Uusitalo-Malmivaara, L., and Di Chiacchio, C. (2017). Burnout in special needs teachers at kindergarten and primary school: investigating the role of personal resources and work well-being. Psychol. Sch. 54, 472-486. doi: 10.1002/pits.22013

Devos, C., Dupriez, V., and Paquay, L. (2012). Does the social working environment predict beginning teachers' self-efficacy and feelings of depression? Teach. Teach. Educ. 28, 206-217. doi: 10.1016/j.tate.2011.09.008

Diener, E., Heintzelman, S. J., Kushlev, K., Tay, L., Wirtz, D., Lutes, L. D., et al. (2017). Findings all psychologists should know from the new science on subjective well-being. Can. Psychol. 58, 87-104. doi: 10.1037/cap0000063

Diener, E., Oishi, S., and Lucas, R. E. (2015). National accounts of subjective well-being. Am. Psychol. 70, 234-242. doi: 10.1002/job.508

Duckworth, A. L., Quinn, P. D., and Seligman, M. E. (2009). Positive predictors of teacher effectiveness. J. Positive Psychol. 4, 540-547. doi: 10.1080/ 17439760903157232

Dutton, J. E., Worline, M. C., Frost, P. J., and Lilius, J. (2006). Explaining compassion organizing. Adm. Sci. Q. 51, 59-96. doi: 10.2189/asqu.51.1.59

Eldor, L., and Shoshani, A. (2016). Caring relationships in school staff: exploring the link between compassion and teacher work engagement. Teach. Teach. Educ. 59, 126-136. doi: 10.1016/j.tate.2016. 06.001

Faulkner, M., Gerstenblatt, P., Lee, A., Vallejo, V., and Travis, D. (2014). Childcare providers: work stress and personal well-being. J. Early Childhood Res. 14, 280-293. doi: 10.1177/1476718X14552871

Field, L. K., and Buitendach, J. H. (2011). Happiness, work engagement and organisational commitment of support staff at a tertiary education institution in South Africa. SA J. Ind. Psychol. 9, 1-10.

Fiorilli, C., De Stasio, S., Benevene, P., Iezzi, D. F., Pepe, A., and Albanese, O. (2015). Copenhagen burnout inventory (CBI). A validation study in an Italian teacher group. Test. Psicometr. Metodol. Appl. Psychol. 22, 507-521. doi: 10. 4473/TPM22.4.7

Fredrickson, B. L. (2001). The role of positive emotions in positive psychology: the broaden-and-build theory of positive emotions. Am. Psychol. 56, 218-226. doi: 10.1037//0003-066X.56.3.218

Fredrickson, B. L. (2013). Positive emotions broaden and build. Adv. Exp. Soc. Psychol. 47, 1-53. doi: 10.1016/B978-0-12-407236-7.00001-2

Fredrickson, B. L., Tugade, M. M., Waugh, C. E., and Larkin, G. R. (2003). What good are positive emotions in crisis? A prospective study of resilience and emotions following the terrorist attacks on the United States on September 11th, 2001. J. Pers. Soc. Psychol. 84, 365-376. doi: 10.1037//0022-3514.84.2.365

Hair, J. F., Black, W. C., Babin, B. J., and Anderson, R. E. (2010). Multivariate Data Analysis: Global Edition. London: Pearson.

Hall-Kenyon, K. M., Bullough, R. V., MacKay, K. L., and Marshall, E. E. (2014). Preschool teacher well-being: a review of the literature. Early Child. Educ. J. 42, 153-162. doi: 10.1007/s10643-013-0595-4

Hareli, S., and Rafaeli, A. (2008). Emotion cycles: on the social influence of emotion in organizations. Res. Organ. Behav. 28, 35-59. doi: 10.1016/j.riob.2008.04.007

Hargreaves, A. (2000). Mixed emotions: Teachers' perceptions of their interactions with students. Teach. Teach. Educ. 16, 811-826. doi: 10.1016/S0742-051X(00) 00028-7

Howard, S., and Johnson, B. (2004). Resilient teachers: resisting stress and burnout. Soc. Psychol. Educ. 7, 399-420. doi: 10.1007/s11218-004-0975-0

Hoy, A. W., and Spero, R. B. (2005). Changes in teacher efficacy during the early years of teaching: a comparison of four measures. Teach. Teach. Educ. 21, 343-356. doi: 10.1016/j.tate.2005.01.007

Hu, L. T., and Bentler, P. M. (1999). Cutoff criteria for fit indexes in covariance structure analysis: conventional criteria versus new alternatives. Struct. Equ. Model. 6, 1-55. doi: 10.1080/10705519909540118

Huynh, J. Y., Xanthopoulou, D., and Winefield, A. H. (2014). The job demandsresources model in emergency service volunteers: examining the mediating roles of exhaustion, work engagement and organizational connectedness. Work Stress 28, 305-322. doi: 10.1080/02678373.2014.936922

Hwang, J. Y., Plante, T., and Lackey, K. (2008). The development of the Santa Clara brief compassion scale: an abbreviation of Sprecher and Fehr's compassionate love scale. Pastoral Psychol. 56, 421-428. doi: 10.1007/s11089-008-0117-2

Ilies, R., Scott, B. A., and Judge, T. A. (2006). The interactive effects of personal traits and experienced states on intraindividual patterns of citizenship behavior. Acad. Manag. J. 49, 561-575. doi: 10.5465/AMJ.2006.21 794672

Iverson, R. D., Olekalns, M., and Erwin, P. J. (1998). Affectivity, organizational stressors, and absenteeism: a causal model of burnout and its consequences. J. Vocat. Behav. 52, 1-23. doi: 10.1006/jvbe.1996.1556

Järvelä, S., Volet, S., and Järvenoja, H. (2010). Research on motivation in collaborative learning: moving beyond the cognitive-situative divide and combining individual and social processes. Educ. Psychol. 45, 15-27. doi: 10. 1080/00461520903433539

Johnson, S. M., Kraft, M. A., and Papay, J. P. (2012). How context matters in highneed schools: the effects of teachers' working conditions on their professional satisfaction and their students' achievement. Teach. Coll. Record 114, 1-39.

Jovanovic, J. (2013). Retaining early childhood educators. Gender Work Organ. 20, 528-544. doi: 10.1111/j.1468-0432.2012.00602.x

Kanov, J. M., Maitlis, S., Worline, M. C., Dutton, J. E., Frost, P. J., and Lilius, J. M. (2004). Compassion in organizational life. Am. Behav. Sci. 47, 808-827. doi: 10.1177/0002764203260211

Kelly, A. L., and Berthelsen, D. C. (1995). Preschool teachers' experiences of stress. Teach. Teach. Educ. 11, 345-357. doi: 10.1016/0742-051X(94)00038-8

Kim, K. S., and Shin, A. S. (2016). 영아교사의 전문성, 민감성, 행복감과 영아-교사 상호작용의 관계 및 영향력 [Relations among infant teachers' professionality, sensibility, and happiness, and infant-teacher interaction, and their effects on infant-teacher interaction. 한국보육학회지. 2:57. doi: 10.21213/kjcec.2016. 16.2 .57

Klusmann, U., Kunter, M., Trautwein, U., Ludtke, O., and Baumert, J. (2008). Engagement and emotional exhaustion in teachers: does school context make a difference. Health Wellbeing 57, 127-151. doi: 10.1111/j.1464-0597.2008. 00358.x

Kokkinos, C. M. (2007). Job stressors, personality and burnout in primary school teachers. Br. J. Educ. Psychol. 77, 229-243. doi: 10.1348/000709905X90344

Kremenitzer, J. P. (2005). The emotionally intelligent early childhood educator: self-reflective journaling. Early Child. Educ. J. 33, 3-9. doi: 10.1007/s10643-0050014-6

Kremenitzer, J. P., and Miller, R. (2008). Are you a highly qualified, emotionally intelligent early childhood educator? YC Young Child. 63, 106-112.

Kyriacou, C. (2001). Teacher stress: directions for future research. Educ. Rev. 53, 27-35. doi: 10.1080/00131910120033628

Lazarus, R. S. (1993). "Coping theory and research: past, present, and future," in Fifty Years of the Research and Theory of RS Lazarus: An Analysis of Historical 
and Perennial Issues, ed. R. S. Lazarus, (Mahwah, NJ: Lawrence Erbaum Associates Inc), 366-388.

Lee, K., and Allen, N. J. (2002). Organizational citizenship behavior and workplace deviance: the role of affect and cognitions. J. Appl. Psychol. 87, 131-142. doi: 10.1037/0021-9010.87.1.131

Leiter, M. P., Day, A., Oore, D. G., and Spence Laschinger, H. K. (2012). Getting better and staying better: assessing civility, incivility, distress, and job attitudes one year after a civility intervention. J. Occup. Health Psychol. 17, 425-434. doi: $10.1037 / \mathrm{a} 0029540$

Lilius, J. M., Worline, M. C., Maitlis, S., Kanov, J., Dutton, J. E., and Frost, P. (2008). The contours and consequences of compassion at work. J. Organ. Behav. 29, 193-218. doi: 10.1002/job.508

Linnenbrink-Garcia, L., Rogat, T. K., and Koskey, K. L. (2011). Affect and engagement during small group instruction. Contemp. Educ. Psychol. 36, 13-24. doi: 10.106/j.cedpsych.2010.09.001

Lorente, L., Salanova, M., Martínez, I. M., and Vera, M. (2014). How personal resources predict work engagement and self-rated performance among construction workers: a social cognitive perspective. Int. J. Psychol. 49, 200-207. doi: 10.1002/ijop.12049

Lucas, R. E. (2007). Adaptation and the set-point model of subjective well-being: does happiness change after major life events? Curr. Dir. Psychol. Sci. 16, 75-79. doi: $10.1111 / j .1467-8721.2007 .00479 . x$

Luhmann, M., Hofmann, W., Eid, M., and Lucas, R. E. (2012). Subjective well-being and adaptation to life events: a meta-analysis. J. Pers. Soc. Psychol. 102, 592-615. doi: $10.1037 / \mathrm{a} 0025948$

Lyubomirsky, S. (2001). Why are some people happier than others? The role of cognitive and motivational processes in well-being. Am. Psychol. 56, 239-249. doi: 10.1037/0003-066X.56.3.239

Lyubomirsky, S., King, L., and Diener, E. (2005). The benefits of frequent positive affect: does happiness lead to success? Psychol. Bull. 131, 803-855. doi: 10.1037/ 0033-2909.131.6.803

Lyubomirsky, S., and Lepper, H. S. (1999). A measure of subjective happiness: preliminary reliability and construct validation. Soc. Indic. Res. 46, 137-155. doi: 10.1023/A:1006824100041

MacKinnon, D. P., Lockwood, C. M., and Williams, J. (2004). Confidence limits for the indirect effect: Distribution of the product and resampling methods. Multivariate Behav. Res. 39, 99-128. doi: 10.1207/s15327906mbr3901_4

Marsh, C. J. (2004). Teaching Studies of Society and Environment. Upper Saddle River, NJ: Prentice Hall.

Mason, V. M., Leslie, G., Clark, K., Lyons, P., Walke, E., Butler, C., et al. (2014). Compassion fatigue, moral distress, and work engagement in surgical intensive care unit trauma nurses: a pilot study. Dimens. Crit. Care Nurs. 33, 215-225. doi: 10.1097/DCC.0000000000000056

Mauno, S., Ruokolainen, M., Kinnunen, U., and De Bloom, J. (2016). Emotional labour and work engagement among nurses: examining perceived compassion, leadership and work ethic as stress buffers. J. Adv. Nurs. 72, 1169-1181. doi: 10.1111/jan.12906

McGinty, A. S., Justice, L., and Rimm-Kaufman, S. E. (2008). Sense of school community for preschool teachers serving at-risk children. Early Educ. Dev. 19, 361-384. doi: 10.1080/10409289.2017.1341806

Miles, D. E., Borman, W. E., Spector, P. E., and Fox, S. (2002). Building an integrative model of extra role work behaviors: a comparison of counterproductive work behavior with organizational citizenship behavior. Int J. Select. Assess. 10, 51-57. doi: 10.1111/1468-2389.00193

Miller, K. I. (2007). Compassionate communication in the workplace: exploring processes of noticing, connecting, and responding. J. Appl. Commun. Res. 35, 223-245. doi: 10.1080/00909880701434208

Morgeson, F. P., and Humphrey, S. E. (2006). The Work Design Questionnaire (WDQ): developing and validating a comprehensive measure for assessing job design and the nature of work. J. Appl. Psychol. 91, 1321-1339. doi: 10.1037/ 0021-9010.91.6.1321

Nislin, M. A., Sajaniemi, N. K., Sims, M., Suhonen, E., Maldonado Montero, E. F., Hirvonen, A., et al. (2016). Pedagogical work, stress regulation and workrelated well-being among early childhood professionals in integrated special day-care groups. Eur. J. Spec. Needs Educ. 31, 27-43. doi: 10.1080/08856257. 2015.1087127

O'Brien, P. J. (2006). Creating compassion and connection in the work place. J. Syst. Ther. 25, 16-36. doi: 10.1521/jsyt.2006.25.1.16
Parker, P. D., Martin, A. J., Colmar, S., and Liem, G. A. (2012). Teachers' workplace well-being: exploring a process model of goal orientation, coping behavior, engagement, and burnout. Teach. Teach. Educ. 28, 503-513. doi: 10.1016/j.tate. 2012.01.001

Peeters, M. A., and Rutte, C. G. (2005). Time management behavior as a moderator for the job demand-control interaction. J. Occup. Health Psychol. 10, 64-75. doi: 10.1037/1076-8998.10.1.64

Pietarinen, J., Pyhältö, K., Soini, T., and Salmela-Aro, K. (2013). Reducing teacher burnout: a socio-contextual approach. Teach. Teach. Educ. 35, 62-72. doi: 10. 1016/j.tate.2013.05.003

Pillay, H., Goddard, R., and Wilss, L. (2005). Well-being, burnout and competence: implications for teachers. Aust. J. Teach. Educ. 30, 21-31. doi: 10.14221/ajte. $2005 \mathrm{v} 30 \mathrm{n} 2.3$

Pomaki, G., DeLongis, A., Frey, D., Short, K., and Woehrle, T. (2010). When the going gets tough: direct, buffering and indirect effects of social support on turnover intention. Teach. Teach. Educ. 26, 1340-1346. doi: 10.1016/j.tate.2010. 03.007

Rentzou, K. (2012). Examination of work environment factors relating to burnout syndrome of early childhood educators in Greece. Child Care Practice 18, 165-181. doi: 10.1080/13575279.2012.657609

Robinson, M. D., Watkins, E. R., and Harmon-Jones, E. (eds) (2013). Handbook of Cognition and Emotion. New York, NY: Guilford Press.

Rodríguez-Muñoz, A., Sanz-Vergel, A. I., Demerouti, E., and Bakker, A. B. (2014). Engaged at work and happy at home: a spillover-Crossover model. J. Happiness Stud. 15, 271-283. doi: 10.1007/s10902-013-9421-3

Saarni, C. (1999). The Development of Emotional Competence. New York, NY: Guilford Press.

Salanova, M., Schaufeli, W. B., Xanthopoulou, D., and Bakker, A. B. (2010). "The gain spiral of resources and work engagement: Sustaining a positive worklife," in Work Engagement: A Handbook of Essential Theory and Research, eds A. B. Bakker, and M. P. Leiter, (New York, NY: Psychology Press), $118-131$.

Salmela-Aro, K. (2009). Personal goals and well-being during critical life transitions: the 4 C's e channeling, choice, co-agency and compensation. $A d v$. Life Course Res. 14, 63-73. doi: 10.1016/j.alcr.2009.03.003

Salmela-Aro, K., Tolvanen, A., and Nurmi, J. E. (2011). Social strategies during university studies predict early career work burnout and engagement: 18year longitudinal study. J. Vocat. Behav. 79, 145-157. doi: 10.1016/j.jvb.2011. 01.002

Schaufeli, W. B., Bakker, A. B., and Salanova, M. (2006). The measurement of work engagement with a short questionnaire: a cross-national study. Educ. Psychol. Meas. 66, 701-716. doi: 10.1177/0013164405282471

Schaufeli, W. B., Salanova, M., González-Romá, V., and Bakker, A. B. (2002). The measurement of engagement and burnout: a two sample confirmatory factor analytic approach. J. Happiness Stud. 3, 71-92. doi: 10.1023/A:1015630 930326

Schermelleh-Engel, K., Moosbrugger, H., and Müller, H. (2003). Evaluating the fit of structural equation models: tests of significance and descriptive goodness-offit measures. Methods Psychol. Res. Online 8, 23-74.

Sharplin, E., O’Neill, M., and Chapman, A. (2011). Coping strategies doi adaptation to new teacher appointments: intervention for retention. Teach. Teach. Educ. 27, 136-146. doi: 10.1016/j.tate.2010.07.010

Simbula, S., Guglielmi, D., and Schaufeli, W. B. (2011). A three-wave study of job resources, self-efficacy, and work engagement among Italian schoolteachers. Eur. J. Work Organ. Psychol. 20, 285-304. doi: 10.1080/135943209035 13916

Sirisunhirun, S., and Dhirathiti, N. S. (2015). Job characteristics and a happy workplace: increasing organisational engagement in thai higher education institutions. Organ. Dev. J. 33, 71-89.

Skaalvik, E. M., and Skaalvik, S. (2011). Teacher job satisfaction and motivation to leave the teaching profession: relations with school context, feeling of belonging, and emotional exhaustion. Teach. Teach. Educ. 27, 1029-1038. doi: 10.1016/j. tate.2011.04.001

Soini, T., Pyhältö, K., and Pietarinen, J. (2010). Pedagogical well-being: reflecting learning and well-being in teachers' work. Teach. Teach. 16, 735-751. doi: 10.1080/13540602.2010.517690

Sprecher, S., and Fehr, B. (2005). Compassionate love for close others and humanity. J. Soc. Pers. Relat. 22, 629-651. doi: 10.1177/0265407505056439 
Staw, B. M., and Barsade, S. G. (1993). Affect and managerial performance: a test of the sadder-but-wiser vs. happier-and-smarter hypotheses. Adm. Sci. Q. 38, 304-331. doi: 10.2307/2393415

Staw, B. M., Sutton, R. I., and Pelled, L. H. (1994). Employee positive emotion and favorable outcomes at the workplace. Organ. Sci. 5, 51-71. doi: 10.1287/orsc.5. 1.51

Stoeber, J., and Rennert, D. (2008). Perfectionism in school teachers: relations with stress appraisals, coping styles, and burnout. Anxiety Stress coping 21, 37-53. doi: 10.1080/10615800701742461

Sutton, R. E., and Wheatley, K. F. (2003). Teachers' emotions and teaching: a review of the literature and directions for future research. Educ. Psychol. Rev. 15, 327-358. doi: 10.1023/A:1026131715856

Tadić, M., Bakker, A. B., and Oerlemans, W. G. (2013). Work happiness among teachers: a day reconstruction study on the role of self-concordance. J. Sch. Psychol. 51, 735-750. doi: 10.1016/j.jsp.2013.07.002

Tehan, M., and Robinson, P. (2009). Leading the way: compassion in the workplace. Illness Crisis Loss 17, 93-111. doi: 10.2190/IL.17.2.b

Tikkanen, L., Pyhältö, K., Pietarinen, J., and Soini, T. (2017). Interrelations between principals' risk of burnout profiles and proactive self-regulation strategies. Soc. Psychol. Educ. 20, 259-274. doi: 10.1007/s11218-0179379-9

Tremblay, M. A., and Messervey, D. (2011). The job demands-resources model: further evidence for the buffering effect of personal resources. SA J. Ind. Psychol. 37, 10-19. doi: 10.4102/sajip.v37i2.876
Underwood, R. A. (2009). U.S. Patent No. 7,491,200. Washington, DC: U.S. Patent and Trademark Office.

Upadyaya, K., Vartiainen, M., and Salmela-Aro, K. (2016). From job demands and resources to work engagement, burnout, life satisfaction, depressive symptoms, and occupational health. Burnout Res. 3, 101-108. doi: 10.1016/j.burn.2016.10. 001

Warr, P. (2007). Searching for happiness at work. Psychologist 20, 726-729.

Xanthopoulou, D., Bakker, A. B., Demerouti, E., and Schaufeli, W. B. (2009). Reciprocal relationships between job resources, personal resources, and work engagement. J. Vocat. Behav. 74, 235-244. doi: 10.1016/j.jvb.2008.11.003

Zimmerman, B. J. (2002). Becoming a self-regulated learner: an overview. Theory Pract. 41, 64-70. doi: 10.1207/s15430421tip4102_2

Conflict of Interest: The authors declare that the research was conducted in the absence of any commercial or financial relationships that could be construed as a potential conflict of interest.

Copyright (C) 2019 De Stasio, Fiorilli, Benevene, Boldrini, Ragni, Pepe and Maldonado Briegas. This is an open-access article distributed under the terms of the Creative Commons Attribution License (CC BY). The use, distribution or reproduction in other forums is permitted, provided the original author(s) and the copyright owner(s) are credited and that the original publication in this journal is cited, in accordance with accepted academic practice. No use, distribution or reproduction is permitted which does not comply with these terms. 